\title{
Detection of Babesia Species from Infected Dog Blood by Polymerase Chain Reaction
}

\author{
Hitoshi ANO $^{1)}$, Susumu MAKIMURA ${ }^{1) *}$ and Ryô HARASAWA ${ }^{2)}$ \\ ${ }^{1)}$ Department of Veterinary Internal Medicine, Faculty of Agriculture, Miyazaki University, Miyazaki 889-2192 and ${ }^{2)}$ Animal Center for \\ Biomedical Research, Faculty of Medicine, University of Tokyo, Hongo, Bunkyo-ku, Tokyo 113-0033, Japan
}

(Received 13 June 2000/Accepted 26 September 2000)

ABSTRACT. Polymerase chain reaction (PCR) was first applied to diagnosis of canine babesiosis in Japan. Blood samples from 13 dogs suffering from canine babesiosis were used for examination of specificity and sensitivity of the PCR diagnosis. Of the 13 dogs, three were experimentally infected, and ten were naturally infected with Babesia species in west part of Japan. We designed a nested PCR to amplify the babesial small subunit ribosomal RNA gene and found that only the nested PCR produced a visual band, which were not apparent by the first-round PCR to the positive samples. Specificity of the nested PCR was confirmed by amplification after the secondround PCR. Sensitivity of the nested PCR was examined by diluting the blood samples from infected and uninfected dogs. The nested PCR was found to show positive results on the most diluted blood at $0.0001 \%$ parasitemia. These results indicate that the nested PCR is highly sensitive and useful for diagnosis of canine babesiosis.

KEY WORDS: babesia, canine, PCR.

J. Vet. Med. Sci. 63(1): 111-113, 2001

Among Babesia species, which infect wide variety of animals, Babesia canis (B. canis) and B. gibsoni have been known as causative agents of canine babesiosis [1, 9, 13, 14]. Clinical findings of canine babesiosis are fever, anorexia, malaise, hemoglobinuria and hemolytic anemia [5, 6, 9, 13], and $B$. canis develops more acute and rapid hemolysis than B. gibsoni [9]. The area of B. canis infection is reported in Southern Europe, North America, Africa and Asia, where $B$. gibsoni is found in Africa and Asia [6, 9, 13]. In Japan, $B$. gibsoni causes mainly canine babesiosis and $B$. canis was reported only in Okinawa [9]. Generally, Babesia species is identified by the demonstrating the organisms in blood smears under the light microscope or by serological examinations [5]. Although the detection of several Babesia species by polymerase chain reaction (PCR) and other DNAbased methods have been reported [2, 4, 6-8, 10-12], these approaches have never been applied on canine babesiosis in Japan. In the present study, we try to detect the small subunit ribosomal RNA (ss-rRNA) of Babesia species from canine blood by PCR. Sensitivity of this method was determined by using diluted blood of Babesia infection.

Blood samples infected with Babesia species were collected from 10 naturally infected dogs in west part of Japan and 3 experimentally infected dogs. A blood sample from uninfected dog was used as a negative control. By microscopic examination of Giemsa-stained blood smears, these 10 dogs were considered infected with $B$. gibsoni because of their size and shape (Fig. 1). Ranges of their parasitemia were estimated from about $1.0 \%$ to $5.0 \%$. DNA was isolated from $200 \mu \mathrm{l}$ of whole blood. Briefly, blood was mixed with $500 \mu l$ of Tris-EDTA (TE) buffer (50 mM Tris, $\mathrm{pH} 8.0,100$ mM EDTA) containing $0.5 \%$ sodium dodecyl sulfate (SDS) and $25 \mu l$ of $10 \mathrm{mg} / \mathrm{m} l$ proteinase K (TaKaRa Shuzo Co.,

\footnotetext{
* Correspondence to: Makimura, S., Laboratory of Veterinary Internal Medicine, Faculty of Agriculture, Miyazaki University, Miyazaki 889-2192, Japan.
}

Ltd., Japan) and incubated at $42^{\circ} \mathrm{C}$. After incubation at overnight, $500 \mu l$ of phenol-equilibrated with TE (10 mM Tris, $1 \mathrm{mM}$ EDTA) was added and spun at 12,000 rpm for $3 \mathrm{~min}$. Aqueous phase was transferred to a fresh tube, and $500 \mu \mathrm{l}$ of phenol-chloroform was added and spun at 12,000 rpm for 3 min. Supernatant fluid was recovered to another tube, and 50 $\mu l$ of $3 \mathrm{M}$ sodium acetate ( $\mathrm{pH}$ 6.0) was added following addition of 1,000 $\mu \mathrm{l}$ cold ethanol. DNA was precipitated by centrifugation at $12,000 \mathrm{rpm}$ for $3 \mathrm{~min}$. After dry the pellet, DNA was dissolved in $10 \mu l$ water and used for PCR. The primers PIRO-F (5'-AGTCATATGCTTGTCTTA-3') and

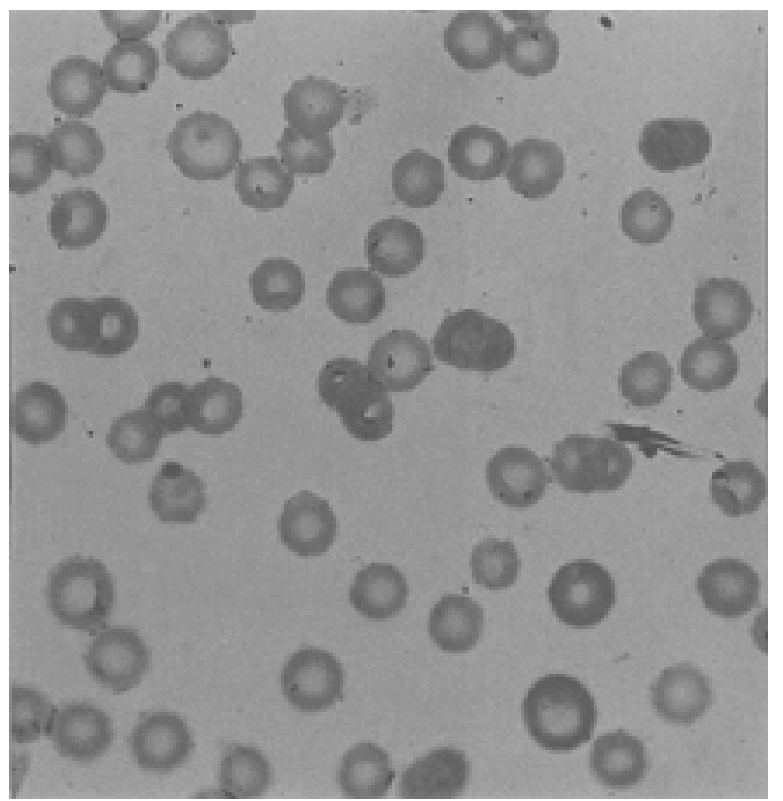

Fig. 1. The light microscopic feature of a Giemsa-stained infected blood smear. Babesia spp. parasites were seen in erythrocytes. $(\times$ $1,000)$ 


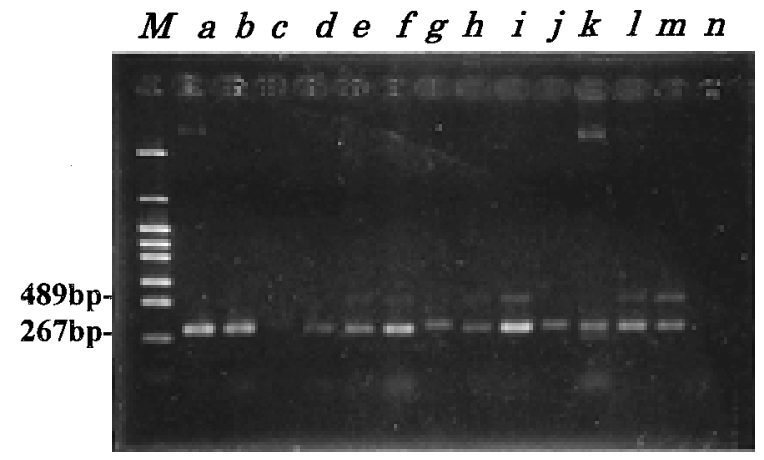

Fig. 2. An ethidium bromide-stained agarose gel of the PCR products from Babesia infected dog blood. Lane $M$ shows a molecular size marker. Lanes from ' $a$ ' to ' $j$ ' are samples from naturally infected dogs and lanes ' $k$ ', ' $l$ ' and ' $m$ ' are from experimentally infected dogs. Lane ' $n$ ' is from an uninfected dog used as a control. In all the infected samples, a band of $327 \mathrm{bp}$ is obvious. Larger bands slightly seen in lanes ' $i$ ' and ' $m$ ' might be produced by incorporating the first-step PCR primers into the second step PCR.

PIRO-R (5'-CCATCATTCCAATTACAA-3'), which amplifies about 500 nucleotides in the small subunit ribosomal RNA gene of $B$. gibsoni, were designed according to the nucleotide sequences in DNA data banks (Gen Bank accession number: L13729). PCR amplification was performed using a programmable thermal cycler (Gene Amp PCR System 2400, Perkin Elmer, U.S.A.). The following conditions were used: After denaturation at $90^{\circ} \mathrm{C}$ for 2 min, 30 cycles of denaturation at $90^{\circ} \mathrm{C}$ for $30 \mathrm{sec}$, annealing at $55^{\circ} \mathrm{C}$ for $2 \mathrm{~min}$ and extension at $72^{\circ} \mathrm{C}$ for 2 min and followed by a final extension at $72^{\circ} \mathrm{C}$ for $5 \mathrm{~min}$. The amplified PCR products were checked on $2 \%$ agarose (SeaKem ME: FMC, U.S.A.) gel electrophoresis and stained with ethidium bromide. A nested PCR was performed using the newly designed inner primers PIRO2-F (5'-ATAACCGTGCTAATTGTAGG-3') and PIRO2-R (5'-TGTTATTTCTTGTCACTACC-3'), which produce 327 bp products, since the first-round PCR products were not visualized as a band. The conditions of the second-round PCR were same as those of the first-round PCR. The results of electrophoresis by the nested PCR were shown in Fig. 2. All the infected samples produced bands of $327 \mathrm{bp}$. To determine the sensitivity of the nested PCR, a blood sample obtained from an experimentally infected dog in about $1.18 \%\left(9.03 \times 10^{4} / \mu l\right.$ of infected erythrocytes) parasitemia, which was diluted by normal canine blood was examined. To examine the sensitivity, the nested PCR was performed on the DNA samples isolated from diluted blood samples (Fig. 3). Detection limit of the sample at the lowest parasitemia was estimated as $0.000118 \%\left(9.93 \times 10^{\%} / \mu l\right.$ of infected erythrocytes).

Canine babesiosis caused by $B$. gibsoni happens often in west part of Japan. Microscopic detection is still the best and most suitable method for on-site diagnosis of acute canine Babesia infection in practical laboratory. However, the accuracy of diagnosis relies on the training and skill of the

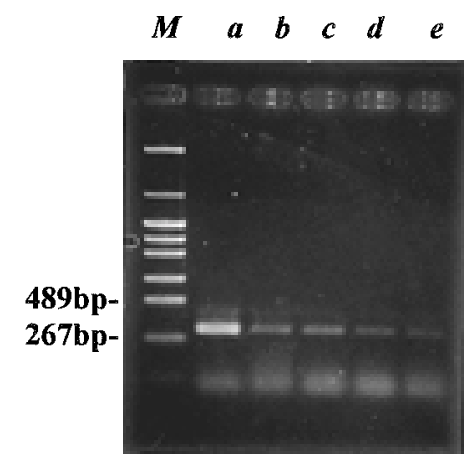

Fig. 3. Sensitivity of the nested PCR to the Babesia species. Lane ' $a$ ' indicates a blood sample of about $1.18 \%$ parasitemia. Samples in lanes from ' $b$ ' to ' $e$ ' were serially tenfold diluted with uninfected dog blood. All the samples from lane ' $a$ ' to lane ' $e$ ' show positive bands. Lane $M$ represents a molecular size marker.

microscopist, especially if the parasitemia are very low [3]. The low parasitemia is appeared in the early stage of the infection or in carrier dogs recovered from the infection [5]. At the moment, the PCR and other DNA-based assays have been widely used as very sensitive and specific methods for the detection of parasites. PCR has been shown to be highly sensitive and specific for the detection of the Babesia species $[2-4,7,8,10,11]$. Although PCR has been used to detect $B$. canis infection [4], the detection of $B$. gibsoni by PCR has not been reported in Japan until today. The first-round PCR products could not be seen as a band after ethidium bromide staining, but the second-round PCR using nested primers produced a visualized band of expected size on each sample (Fig. 2). PCR-based detection of babesial DNA in canine blood was significantly amplified by incorporating a nested protocol. Babesia organism used in this experiment is a very small in size with a little amount of chromatin (Fig. 1). The infected blood might contain so little DNA content that the first-round PCR could not detect. From these results, this nested PCR approach is useful to find the infection of canine babesiosis with low parasitemia including carriers because of its high sensitivity.

\section{REFERENCES}

1. Adachi, K. and Makimura, S. 1992. J. Vet. Med. Sci. 54: 12211223.

2. Allsopp, M. T. E. P., C-Smith, T., de Waal, D. T. and Allsopp, B. A. 1994. Parasitology 108: 147-152.

3. Böse, R., Jorgensen, W. K., Dalgliesh, R. J., Friedhoff, K. T. and de Vos, A. J. 1995. Vet. Parasitol. 57: 61-74.

4. Carret, C., Walas, F., Carcy, B., Grande, N., Precigout, E., Moubri, K., Schetters, T. P. and Gorenflot, A. 1999. J. Eukaryot. Microbiol. 46: 298-303.

5. Conrad, P., Thomford, J., Yamane, I., Whiting, J., Bosma, L., 
Uno, T., Holshuh, H. J. and Shelly, S. 1991. J. Am. Vet. Med. Assoc. 199: 601-605.

6. Conrad, P. A., Thomford, J. W., Marsh, A., Telford III, S. R., Anderson, J. F., Spielman,A., Sabin, E. A., Yamane, I. and Persing, D. H. 1992. J. Clin. Microbiol. 30: 1210-1215.

7. Ellis, J., Hefford, C., Baverstock, P. R., Dalrymple, B. P. and Johnson, A. M. 1992. Mol. Biochem. Parasitol. 54: 87-96.

8. Fahrimal, Y., Goff, W. L. and Jasmer, D. P. 1992. J. Clin. Microbiol. 30: 1374-1379.

9. Farwell, G. E., LeGrand, E. K. and Cobb, C. C. 1982. J. Am. Vet. Med. Assoc. 180: 507-511.

10. Figueroa, J. V., Chieves, L. P., Johnson, G. S. and Buening, G.
M. 1992. J. Clin. Microbiol. 30: 2576-2582.

11. Persing, D. H., Mathiesen, D., Marshall, W. F., Telford, S. R., Spielman, A., Thomford, J. W. and Conrad, P. A. 1992. J. Clin. Microbiol. 30: 2097-2103.

12. Reddy, G. R. and Dame, J. B. 1992. J. Clin. Microbiol. 30: 1811-1814.

13. Ristic, M. 1988. In: Babesiosis of Domestic Animals and Man. CRC Press, Inc., Florida.

14. Schetters, T. P. Moubri, K., Precigout, E., Kleuskens, J., Scholtes, N. C. and Gorenflot, A. 1997. Parasitology 115: 485493. 